\title{
CORPORALIDADE EM CONFRONTO Brasileiras na indústria do sexo na Espanha
}

\section{Adriana Piscitelli}

\section{Apresentação}

Na Vila Olímpica, frente à marina, há uma sucessão de bares, restaurantes, discos... Há dois bares, me disseram, freqüentados por garotas brasileiras que fazem programas. Um deles está lotado. Na entrada, há um coqueiro feito de luzes verdes e amarelas. É amplo, tem uma pista de dança e plataformas elevadas. O público é diversificado. O ambiente é pesado e um pouco assustador. Uma jovem de pele cor de chocolate, curvas acentuadas, cabelo enorme, sapatos brancos com saltos muito altos, mini-saia de jeans bem justa e top, dança em uma das plataformas. Ela rebola as cadeiras com movimentos altamente erotizados. Minha acompanhante acha que ela é brasileira. Mas, quando desce, a menina explica que é espanhola, filha de uma cubana.

Em outra plataforma, uma garota loura, esguia, de corpo retilíneo, pele muito branca e cabelos compridos, com mini-saia, também dança. Seu aspecto

Artigo recebido em outubro/2005

Aprovado em novembro/2006 sugere que é do Leste Europeu. Há uma enorme diferença no estilo corporal e nos movimentos das duas. Os da jovem loura se concentram na parte superior do corpo. Mexe os ombros, mas praticamente não ondula as cadeiras. Enrosca-se em um pau de metal, subindo e descendo, como nos shows de strip-tease, mas aqui ela não tira a roupa. À maneira dos clubs de alterne espanhóis, esta disco parece utilizar como apelo a oferta visual de mulheres, de diferentes lugares do mundo, com diversos estilos de corporalidade. Nesse lugar não vi nenhuma mulher negra (Diário de campo, Barcelona, 6 de novembro, 2004).

Este trecho de diário de campo, sugerindo a implementação de um apelo erótico ancorado na diversidade (étnica/"racial"), foi escrito durante uma pesquisa sobre a inserção de brasileiras na indústria do sexo na Espanha. ${ }^{1}$ Neste trabalho trato da construção desse estilo de erotização, explorando como gênero e corporalidade se integram na concorrência que permeia o mercado do sexo contemporâneo. 
Constituído pelo jogo entre oferta e demanda de serviços sexuais, esse mercado e a organização empresarial em torno dele estão marcados pelo caráter transnacional. Refiro-me aos processos de atravessar as fronteiras para consumir e oferecer serviços sexuais (Agustín, 2001, 2005; Piscitelli, 2005), nos quais se estabelecem relações complexas entre diversos locais, incluindo redes e laços sociais entre o local de origem e os diferentes destinos. ${ }^{2}$ Refiro-me também à participação dos capitais que sustentam a indústria do sexo. Este termo, utilizado para designar a estrutura organizativa vinculada ao mercado do sexo, destaca tanto a solidez dessa organização como as forças econômicas e os interesses que a impulsionam (Lim, 2004). ${ }^{3}$ Tomando como referência a inserção de brasileiras na indústria do sexo na Espanha, analiso o jogo de relações que, nesse marco, opera na produção de configurações corporais. ${ }^{4}$

Esta análise está baseada em uma pesquisa exploratória, realizada em uma perspectiva antropológica, que incluiu o trabalho de campo entre outubro e dezembro de 2004 e setembro de 2005.

$5 \mathrm{Na}$ primeira parte, faço alguns comentários sobre noções vinculadas à difusão de imagens do Brasil através das fronteiras. Na seqüência, trato das trajetórias dessas mulheres, considerando as implicações culturais, políticas e econômicas dessa modalidade de migração. Finalmente, criando uma perspectiva comparativa a partir das conceitualizações acionadas nos relacionamentos entre estrangeiros e brasileiras no marco da indústria do sexo no Brasil, considero como a alteração de contextos incide nos significados concedidos às diferenças que permeiam os encontros com consumidores de sexo na Espanha. Essa questão é elucidada explorando como construções de gênero, nacionalidade/etnicidade, "raça", classe e idade são acionadas nas interações comerciais estabelecidas por essas migrantes.

\section{Imagens do Brasil através das fronteiras}

Nas discussões socioantropológicas, a vinculação entre certas regiões pobres do mundo e a prostituição é considerada efeito das viagens de turistas sexuais aos países do "Terceiro Mundo", da ampliação do uso da Internet, tida como espaço privilegiado para a criação e a difusão de imagens sexualizadas e racializadas desses lugares e, ainda, da migração de mulheres do Sul para trabalharem em night clubs e bordéis em todo o mundo (Thorbek e Pattanaik, 2002). Considera-se que na "nova ordem global" (Appadurai, 1996), na qual marcas de gênero cada vez mais sutis informam a recriação de desigualdades em escala mundial, a difusão dessas imagens e a intensificação na mobilidade estimulam e facilitam o consumo da alteridade em qualquer lugar do mundo. Nesse processo, as (antigas) relações entre erotismo e exotismo (Leclerc, 1976) adquirem novos conteúdos (Kempadoo, 2004).

A discussão sobre a integração de brasileiras no mercado transnacional do sexo está permeada por algumas dessas noções. No debate público brasileiro uma certa construção da feminilidade nacional, intensamente sexualizada e marcada pela "cor", é um aspecto central na dinâmica do turismo sexual internacional, da prostituição de brasileiras no exterior e do tráfico internacional de mulheres. O suposto é que essa construção, originada nas imagens de mulatas e negras historicamente produzidas no Brasil e difundidas no exterior (Dias Filho, 1998), explica uma elevada demanda de mulheres do país. Essas imagens, associadas a certos traços fenotípicos, vinculados a mulheres de pele escura, como os que constituem a figura da mulata (Corrêa, 1996), teriam se disseminado no exterior (Cecria, 2000).

Os estudos sobre a circulação de imagens corporais de brasileiros/as através das fronteiras apresentam, porém, um quadro mais complexo. De acordo com essas pesquisas, tais imagens não reiteram aquelas que, presentes no Brasil, foram utilizadas para difundir o país no exterior, inclusive em propagandas oficiais, até poucos anos atrás (Emrich Pinto, 2005; Alfonso, 2006). No âmbito transnacional, elas tendem a ser erotizadas por meio de uma construção de nacionalidade atravessada por gênero que é racializada e sexualizada, mas não necessariamente associada às "cores" de pele escura (Pontes, 2004; Piscitelli, 2004). E a operação desse jogo de categorias aparece na percepção sobre as brasileiras inseridas ou não na indústria do sexo. 
As dançarinas go-go em New Jersey, originárias de camadas médias no Brasil, com educação superior, de tons de pele claros, analisadas por Susana Maia (2007) oferecem um exemplo desses processos. De maneira análoga, a imagem da empregada doméstica brasileira exibida na mídia portuguesa, "uma mulher fatal", posicionada em uma classe inferior, é incorporada numa mulher branca. Segundo Luciana Pontes (2004), nos novos processos de construção da etnicidade brasileira em Portugal, vinculados às migrações atuais, essa etnicidade está marcada pela posição de classe no país de destino e associada a uma ideologia da mestiçagem exotizada e sensualizada. As agentes, porém, não precisam ser mestiças: sua brasilidade já lhes confere essa filiação.

A recorrência de uma construção de etnicidade brasileira relativamente autônoma dos traços fenotípicos não significa, porém, que os significados a ela atribuídos sejam os mesmos em diferentes contextos migratórios. Machado (2003), em uma observação que compartilho, chama a atenção para a existência de processos de exotização diferenciados, segundo as sociedades de recepção dos migrantes.

Neste texto argumento que para entender as relações das imagens sobre o Brasil com a inserção das brasileiras no mercado transnacional do sexo é necessário prestar séria atenção aos cenários nos quais as convenções eróticas se materializam. Nos deslocamentos para consumir ou oferecer serviços sexuais, imagens corporais, escolhas e práticas sexuais apresentam aspectos diversificados. A materialidade simbólica envolvida nesse tipo de mercado assume traços particulares em diferentes espaços de interação, no Brasil e no exterior, que são delineados em relação à localização geopolítica dos agentes e a seu posicionamento na indústria do sexo no país em questão. Compreender os vínculos entre exotismo e erotismo requer considerar as convenções que, nesses contextos, permeiam as interações entre consumidores e "vendedores/as".

\section{Brasileiras na indústria do sexo na Espanha}

As brasileiras entrevistadas estão inseridas em distintos segmentos da indústria do sexo na
Espanha. De acordo com estudos sobre a temática, as modalidades de trabalho nessa indústria são diversificadas, incluindo linhas telefônicas eróticas, peep shows, espaços de espetáculo erótico, a Internet, locais de strippers e os serviços sexuais resultantes de encontros em bares, estradas, rua, clubes e pisos (apartamentos) (Pons, Rodríguez e Vega, 2002). Nesta pesquisa, centrei-me em mulheres que trabalham nesses três últimos tipos de locais: rua, clubes e pisos.

Os serviços sexuais que têm lugar a partir desses espaços apresentam diversas nuanças. Contatos acertados durante o dia e no início da noite, na rua, podem ser realizados em mueblés e, nas madrugadas, dentro de carros ou em lugares afastados. Os pisos divergem em sua organização, na população que neles trabalha (alguns são ocupados exclusivamente por mulheres, outros por "trans") e no "nível", expressado nos valores dos serviços. Entre os clubs, há uma ampla diversidade: em um pólo estariam os estabelecimentos "tradicionais", cujo lucro provém da venda de bebidas e/ou de receber um percentual dos serviços prestados, espaços que contam com bar, pista de dança e nos quais as mulheres circulam, saindo deles ou entrando em "reservados". No outro extremo, os novos hotéis-plaza. Os clubes de estrada tradicionais, localizados nas periferias dos povoados, com aproximadamente dez mulheres trabalhando começaram a fechar no início dos anos de 1990, substituídos por outros maiores com ascendente "filosofia empresarial" (Pons, Rodríguez e Veja, 2002). Neles podem trabalhar até 150 mulheres, ocupando vagas por períodos de 21 dias (Pons, 2003). O lucro dos proprietários reside no valor que as mulheres pagam pela utilização do hotel e pela alimentação. Em 2004, essa diária estava em torno de 40 a 60 euros. Para se ter uma referência, o valor dos serviços prestados durante meia hora nesses clubes era aproximadamente 60 euros, enquanto pelo mesmo período de tempo, na rua, era, aproximadamente, 30 euros. ${ }^{6}$ No momento, avalia-se que a rua concentra um número trabalhadores sexuais significativamente inferior aos que ofereceram serviços em clubes ou "hotéis", com percentuais que variam em regiões e cidades.?

As entidades que apóiam trabalhadoras/es do sexo consideram que na Espanha, como em 
outros países da Europa, o perfil da prostituição mudou ao longo da década de 1990; hoje é uma atividade desempenhada, sobretudo, por estrangeiras. ${ }^{8}$ Não há um acordo sobre o percentual de estrangeiras, o que não surpreende, uma vez que os estudos limitam-se a nichos ou modalidades de serviços em regiões específicas e, além disso, costumam divergir nas metodologias utilizadas. ${ }^{9}$ Os relatórios existentes sobre modalidades específicas de trabalho sexual apontam para uma maioria de pessoas estrangeiras, de diversos lugares do mundo. No entanto, é importante registrar que a alteração na nacionalidade das prestadoras de serviços sexuais é considerada análoga à modificação entre prestadores de serviços em outros setores, como o doméstico, de pesca e agricultura.

As leituras mais cautelosas sobre a presença de estrangeiras na indústria do sexo na Espanha avaliam que a mesma, ainda em ascensão, já supera o patamar de 50-60\% e chamam a atenção para a exagerada repercussão e para o vitimismo que permeiam afirmações sobre percentuais mais elevados (Pons, 2003; Agustín, 2001). No quadro dessas variações, diversos relatórios apontam para a significativa presença de latino-americanas, particularmente em algumas regiões. ${ }^{10}$ Mas, seria inútil tentar oferecer cifras. As características da atividade (a clandestinidade, agravada quando os prestadores de serviços são migrantes irregulares, e ampla mobilidade dos/as que prestam serviços sexuais) fazem com que as estatísticas sobre prostituição e sobre tráfico não passem de estimativas. No que se refere às brasileiras, a isto se soma o fato de que vários dos estudos classificam as mulheres em categorias amplas, referidas a continentes ou regiões e não à nacionalidade.

Em termos de cifras relativas a migrantes regulares, o Boletim estadístico de extranjeria y inmigración (n. 3, 2004) informa que em junho de 2004, as brasileiras, $71,07 \%$ do total de brasileiros legalmente residindo na Espanha, totalizavam 11.153 (um número pequeno quando comparado com o de outras latino-americanas: colombianas, 72.284, e equatorianas, 94.541). As pesquisas sobre migrações, porém, mostram a enorme diferença entre os migrantes com permissão de residência e os empadronados (que registraram seu domicilio na Espanha com algum fim, sobretudo para ter acesso à assistência médica). No caso de cidadãos do Equador e da Argentina, essa diferença supera os 200\% (Terrón, 2004). Nos estudos que exploram essa diferença não há um levantamento análogo para os brasileiros, talvez porque seu número não seja tão elevado quanto o de outros cidadãos latino-americanos. Mas é possível pensar na diferença entre o número de brasileiros regulares e irregulares considerando a estimativa de agentes do consulado brasileiro em Barcelona. Na região atendida por esse órgão, em 2004, havia aproximadamente 10 mil brasileiros (2500 novos registros correspondiam ao ano de 2004) e outros tantos seriam atendidos pelo consulado de Madri.

Segundo esses agentes, o consulado recebe mais solicitações de documentação de mulheres para contrair matrimônio do que de homens. Entre cinco e seis solicitações semanais, número equivalente, no período em que a pesquisa foi realizada, ao de deportações de brasileiras das quais o Consulado tinha notícia. ${ }^{11}$

Entre os agentes entrevistados, há um acordo significativo: considerar que o número de brasileiras oferecendo serviços sexuais na rua é relativamente reduzido quando comparado a mulheres de outras nacionalidades. Em contrapartida, sua presença cresce em espaços fechados, como pisos e, sobretudo, clubes. ${ }^{12}$ A leitura dos depoimentos registrados no site espanhol para clientes (www.hotvalencia.com) sustenta as impressões sobre a presença das brasileiras nesses espaços. As trocas de mensagens dos usuários sobre mulheres que trabalham em pisos de Valência também são significativas: dos 298 registros, 133 referem-se a brasileiras e 62, a mulheres de outros países da América Latina. ${ }^{13}$

Essa impressão é referendada pelo representante da Asociación Nacional de Clubes de Alterne (Anela), em Barcelona. ${ }^{14}$ Segundo ele, nos estabelecimentos vinculados à entidade em todo o país, em 2004 havia aproximadamente 14 mil mulheres oferecendo serviços sexuais. Delas, 40\% seriam russas, romenas, da antiga Iugoslávia, tchecas. As mulheres latino-americanas, principalmente brasileiras e colombianas, representariam os outros $40 \%$, embora com a presença, também, de uruguaias, dominicanas, venezuelanas e, muito ocasionalmente, argentinas. Já as africanas, nitidamente inferiorizadas, teriam uma presença menor. Segundo ele: 
En los clubs hay alguna que otra nigeriana, pero muy pocas, porque quitan categoría a los lugares, son muy sin cultura, hay dos o tres, porque siempre hay algún cliente al que le gustan las chicas más salvajes. Y en la calle ellas son las que cobran menos.

Os estudos sobre migração dificilmente prestam atenção nos deslocamentos para trabalhar na indústria do sexo (Agustín, 2006). Mas, se brasileiras e colombianas ${ }^{15}$ ocupam espaço equivalente nesses clubes, a grande diferença numérica entre mulheres das duas nacionalidades na Espanha no período em que foi realizada a pesquisa sugere que a inserção na indústria do sexo pode ser uma estratégia relevante de migração para as brasileiras que partem em direção àquele país.

\section{Trajetórias}

As entrevistadas brasileiras que oferecerem serviços sexuais na Espanha estão marcadas pela diversidade em termos da inserção na indústria do sexo (incluindo modalidades, ritmo e condições de trabalho), da idade, dos estados de origem, da "cor", do tempo e da condição de permanência no país. Essas diferenças e o fato de residirem em diferentes cidades são fatores que impossibilitam realizar generalizações tendo como referência esse universo. No entanto, no quadro dessa pluralidade manifestam-se sugestivas regularidades no que concerne à percepção das mesmas sobre as imagens criadas em torno delas.

Algumas têm hoje em torno de 20 anos, mas ingressaram na indústria do sexo na Espanha recém-saídas da adolescência; outras estão na faixa dos 30 anos; e outras, ainda, chegaram ao país com mais de 40 anos.

A escolaridade tende a ser relativamente baixa, entre o primeiro grau incompleto e o segundo completo. Apenas uma iniciou o curso superior. Os estados de origem são diversificados: Rio Grande do Sul, Goiás, Bahia, Pernambuco, Rio Grande do Norte, Minas Gerais e São Paulo. Algumas migraram para Espanha depois de terem morado em outros estados.

Algumas, antes de migrar para Europa, já sobreviviam exclusivamente da prostituição no Brasil, outras fizeram programas durante um breve período de tempo no âmbito do turismo sexual no Nordeste do Brasil, mas a maioria delas já tinha oferecido algum tipo de serviço sexual no Brasil, e migrou com este objetivo em mente. Chegaram diretamente em Madri, ou passaram antes por Paris, dirigindo-se, em seguida, a cidades nas quais tinham contatos: o endereço de um clube fornecido por um agenciador ou por alguma amiga ou conhecida.

Algumas, contatadas em lugares onde já ofereceriam serviços sexuais para estrangeiros, migraram mediante contato com intermediadores vinculados a clubes espanhóis (taxistas brasileiros ou agenciadores estrangeiros); outras, contudo, estavam inseridas em redes femininas de vizinhas, amigas, conhecidas e parentes que já moravam na Espanha, o que também é recorrente para migrantes de outras nacionalidades (Oso Casas, 2005), assim como para pessoas transexuais.

A migração com vistas à inserção na indústria do sexo envolve muitas vezes redes semelhantes às usadas por migrantes brasileiros que trabalham em outros setores e, no passado, de migrantes internos, do Norte e Nordeste do Brasil para o Sudeste do país. Nesses casos, o adiantamento do dinheiro a ser devolvido com juros análogos aos pagos em um clube, a oferta de uma vaga em um apartamento (pela qual se paga um valor superior ao que ela de fato teria) e/ou o apoio para se estabelecer em "pontos" na rua, tudo isso é lido como "ajuda".

Entre as entrevistadas há também mulheres que migraram com o objetivo de trabalhar em outro ramo de atividade, mas que optaram por uma mudança de plano, quando já estavam na Europa, ao avaliarem que poderiam obter maiores recursos financeiros por meio da inserção na indústria do sexo. O deslocamento entre outra atividade no setor de serviços e a prostituição é uma possibilidade que aparece como permanentemente aberta e tentadora, e está longe de restringir-se às migrantes brasileiras (Casas e Jimenez, 2001). Compreender tal sedução exige considerar a dificuldade, enfrentada pelos migrantes irregulares, para obter emprego e o grau extremo de exploração ao qual são submetidos quando o obtém. ${ }^{16}$

As mulheres, as que estão de maneira regular na Espanha obtiveram os "papéis" através do casamento com espanhóis, clientes ou não. As 
outras estão irregulares ou passam uns meses na Espanha e retornam ao Brasil para regressar novamente à Espanha.

As rendas que declaram receber pelos serviços sexuais oscilam entre 2.500 e 5 mil euros por mês. Embora o trabalho na rua seja considerado de um nível "inferior" à prostituição que tem lugar em clubes e pisos, as diferenças na renda aparecem, sobretudo associadas à maturidade e à capacidade de administrar o dinheiro. Aliás, as preferências por uma ou outra modalidade de prostituição são variadas. Entrevistadas mais jovens preferem trabalhar em clubes com certa clientela e condições de trabalho percebidas como mais adequadas, devido à convivência e sociabilidade com outras garotas da mesma idade e, com isso, um clima de diversão. As mulheres mais velhas, que já passaram por clubes, ao contrário, preferem a rua, no período diurno. Segundo elas, apesar de cobrarem por um programa quase a metade do que se cobra em um clube, suas rendas são equivalentes, porque são exclusivamente para elas. Além disso, as condições de trabalho são mais flexíveis.

Os rendimentos mensais dessas entrevistadas, particularmente das que trabalham na rua, recebendo clientes de menores recursos, podem ser superiores aos de seus clientes. Os níveis de renda mostram, portanto, a necessidade de categorias alternativas para refletir sobre as distribuições diferenciadas de poder que permeiam a inserção dessas mulheres na indústria do sexo na Espanha. A noção de localização, como marco estrutural no qual situar as posições desiguais vinculadas às nacionalidades em jogo é relevante para pensar estas interações. No caso das migrantes que trabalham na indústria do sexo, o posicionamento é ainda mais frágil nos (muitos) casos em que não estão em situação regular. E, irregulares ou não, isto se agrava devido à estigmatização da prostituição (Garaizabal, 2005), na percepção das entrevistadas, maior ainda do que no Brasil. ${ }^{17}$ De acordo com uma delas:

No Brasil, se sabe que quem está nisso é porque precisa. As mulheres vivem para a família, trabalham para sustentar filho, irmãos. Aqui, quem está na prostituição e é espanhola, é para manter vícios. Droga, jogo, máquinas traga perras. E, no fundo, acho que há algo de verdadeiro nisso. Quem nasce na Europa não precisa se prostituir, pode fazer qualquer outra coisa. Já no Brasil, não.

Assim como os migrantes brasileiros inseridos em outros setores do mercado de trabalho em todo o mundo (Assis, 2004), estas também mantêm estreitos laços com o Brasil. A comunicação telefônica é intensa, as visitas ao Brasil, no caso das que têm "papéis", é freqüente. E também o é a circulação de parentes, irmãs, primas. Parte substantiva dessa comunicação exprime-se em remessas que são manifestação de carinho e, simultaneamente, da obrigação criada pelos laços de parentesco. Elas são enviadas ao Brasil via agências de câmbio particulares (jamais um banco brasileiro), em valores que oscilam entre 100 e 1500 euros mensais, para sustentar filhos, mães, sobrinhos, cobrindo gastos os mais variados (telefone, gás, material escolar, até a mensalidade da faculdade) e para investimentos diversificados no país. E, se as condições econômicas são determinantes para a inserção dessas entrevistadas na indústria do sexo na Espanha, isto não significa necessariamente aludir a uma situação miserável no Brasil. Trata-se, sobretudo, da falta de possibilidade que elas sentem em termos de planejar o futuro, em termos econômicos, para elas e para seus descendentes.

Os projetos elaborados no traçado desse futuro são diversificados, mas tendem a estar associados ao retorno ao Brasil. Com esses objetivos, as entrevistadas enfrentaram o estigma associado à prostituição, em muitos casos a "irregularidade", as dificuldades de aprendizagem da língua, de procura de moradia, a distância cultural com os espanhóis e, sobretudo, as espanholas e migrantes de outras nacionalidades, além da difícil relação com as estrangeiras com as quais disputam clientes no mesmo mercado.

\section{Consumo erótico e trasnacionalidade}

Uma pessoa ligada à Asociación de los Clubs de Alterne em Barcelona me recebe em um apartamento imenso, em estilo modernista, cheio de obras de arte. O lugar cheira a dinheiro e requinte. Conversamos sobre o lugar das brasileiras nos Clubs. Na visão dele, constituem um grupo significativo, mas é mais um entre outros. Comento com ele as diferenças entre o quadro que está sendo 
traçado por mim na Espanha e os resultados do meu trabalho sobre turismo sexual no Brasil. Ele reflete um instante e logo diz:

"Es que los que van a turismo sexual a Brasil están buscando brasileñas que son mujeres por naturaleza sensuales, cariñosas [...].

La brasileña... es cariñosa. Pero aquí, el cliente quiere el mejor rendimiento en el menor tiempo, y, en ese sentido, las mujeres del Este Europeo tienen más salida, porque son mucho más profesionales. En Brasil es más una cuestión de naturaleza" (Diário de Campo, Barcelona, 4 de novembro, 2004).

Para entender como corporalidade e gênero se integram na "concorrência" por clientes, é preciso analisar a maneira pela qual as convenções de erotização que marcam a brasilidade adquirem conotações particulares na Espanha e em nichos específicos da indústria do sexo nesse país. Uma leitura comparativa da maneira como esses jogos de categorias são corporificados em um contexto de turismo sexual no Brasil oferece elementos para refletir sobre as especificidades dessas convenções. Refiro-me a Fortaleza, cidade na qual estudei uma modalidade de "turismo sexual" (Piscitelli, 2004). ${ }^{18}$

Nesse contexto, os corpos são produzidos na imbricação de noções de feminilidade e masculinidade vinculadas à origem nacional, "raça", classe e idade, em processos nos quais as mulheres nativas são intensamente sexualizadas e os estrangeiros são considerados a corporificação dos estilos mais valorizados de masculinidade. No quadro de viagens à procura de "autenticidade", a exotização das nativas se expressa na atribuição de um valor positivo a estilos de feminilidade "tradicionais" associados a uma intensa sexualização, animando corpos com marcas claramente delineadas no que se refere à juventude, aos traços faciais, o tipo de cabelo, as formas da silhueta e, sobretudo, a "cor", morena.

As nativas tendem a serem singularizadas em relação a mulheres de outros destinos dos circuitos globais de turismo sexual, na base de noções de intensidade sexual, associada à disposição para o sexo, que se expressa em qualquer prática sexual, até as mais banais, por exemplo, nos estilos de beijar. O clima de erotismo que perpassa esses relacionamentos, longe de estar vinculado a práticas sexuais necessariamente pensadas como extremas ou anômalas é produzido por uma combinação entre essa intensidade e transgressões situadas em outros planos: nas possibilidades da procura de um prazer inteiramente desvinculado de investimentos afetivos, ou, ao contrário, de unir o prazer sensual aos sentimentos. Nesse último caso, podem conduzir ao casamento, e com ele realizar um duplo movimento: introduzir a extrema paixão carnal na conjugalidade e interromper convenções homogâmicas e homocromáticas. Nesse universo, as técnicas corporais desenvolvidas pelas mulheres nativas reiteram a idéia de um saber sexual específico, vinculado à intensa sexualização e à "cor" a elas atribuídas pelos visitantes estrangeiros.

Nos processos migratórios de nativas que supostamente corporificam a "sexualidade tropical" para os países do Norte, porém, as imagens corporais e as práticas sexuais envolvidas no consumo sexual não se mantém estáveis. Nesse deslocamento de contextos, as convenções que permeiam a corporalidade são re-significadas, atingindo de diversas maneiras as brasileiras que se inserem no mercado do sexo na Europa, em países cujas relações históricas com o Brasil são diferentes.

$\mathrm{Na}$ Espanha, a visibilidade do Brasil e a integração da brasilidade na conformação das convenções corporais e eróticas aparece de maneira mais diluída que em outros países europeus, como a Itália, também emissores de turistas sexuais para o Brasil. Tomando como referência Milão e Barcelona, capitais de regiões que atraem brasileiras para inserir-se na indústria do sexo, uma comparação entre ambas cidades mostra que a aparente incidência do país na moda-praia e na prestação de serviços corporais em sentido amplo (aulas de dança, samba-terapias, capoeira) é mais intensa na cidade italiana. Na Lombardia, as brasileiras aparecem, entre as latino-americanas, como privilegiadas por essa vinculação (Piscitelli, 2007). $\mathrm{Na}$ Catalunha, porém, essa relação, parece apontar, sobretudo, para "morenas" das ex-colônias espanholas, com destaque, de acordo com regiões, locais e "níveis", para colombianas e cubanas. Precisamente essas nacionalidades são apontadas por algumas entrevistadas como as mais sérias concorrentes. De acordo com uma paulista de 28 anos, esguia, de cabelos e pele 
claros (que, curiosamente, se recusou a falar em português) que já trabalhou em clubes em diversas partes da Espanha e agora oferece serviços em pisos em Barcelona:

No hay muchas cubanas, pero hay... Tenemos mucho en común las brasileras y las cubanas, la religión... es la misma, eso de bailar, somos muy parecidas. Pero claro, en el piso, a ver, las cubanas son $\tan$ calientes cuanto las brasileras, entonces [risas] la competencia... mas aún que [con] las colombianas, yo creo que por eso no hay mucha amistad... Una colombiana, una ecuatoriana por ser latinas tienen mas proximidad entre ellas, pero las brasileñas como que son latinas, pero "soy latina pero no soy como vosotras" [...].

\section{Concorrências}

A concorrência na indústria do sexo, tida como "feroz", é assinalada nos estudos sobre o tema na Espanha, com destaque para as regiões em que há trabalhadoras do sexo de várias nacionalidades (Oso Casas e Ulloa Jiménez, 2001). Em um ranking organizado com a utilização de diversos "traços" (juventude, beleza, educação e nacionalidade), a hierarquia seria encabeçada pelas espanholas, seguidas por mulheres do Leste Europeu, latino-americanas e, em último lugar, africanas (Pons, Rodriguez e Vega, 2002). De acordo com Pons (2003), na Catalunha, os empresários classificam as trabalhadoras na base de noções que consideram latino-americanas e africanas mulheres que, "com o sexo a flor da pele", têm uma predisposição natural para ele. Isso não aconteceria com as mulheres do Leste Europeu, que, tidas como mais cultas, de mais categoria, seriam as preferidas dos europeus.

As mulheres concorrem nesse contexto criado pelos critérios de empresários e clientes. De acordo com a jovem paulista:

Entre los clientes y entre las chicas se crean estos mitos de cada nacionalidad... Yo noto que en los clubes las españolas trabajan mas, incluso hay algunos que van a buscar españolas... catalanas, porque no quieren estar con extranjeras. Pero depende... A unos les encantan las brasileras. A otros les gustan las rusas, que normalmente hacen otro tipo de servicios, como las rumanas... prácticas de riesgo... Yo entré en la habitación con una rusa, son como frías en la cama... pero tipo así, hacía unas cosas! Brasilera, que para ellas es mas caliente, no las hace.

Nas discussões do site já mencionado, nas quais os clientes descrevem suas experiências, o item nacionalidade faz parte do leque de questões que incluem perguntas referidas ao corpo, rosto, idade da garota, práticas sexuais e atitudes em relação a essas práticas e de repetir ou não a experiência com a mesma garota.

Os clientes, porém, não constituem uma categoria homogênea. As distinções entre consumidores de sexo que freqüentam clubes em diferentes regiões da Espanha são marcadas pela jovem paulista:

En ese sitio, en Almeria... los clientes, la mayoría, eran gitanos y marroquíes, que para nosotras son los peores clientes que hay porque... ponen el cuchillo en el cuello de las chicas. Claro, en cada nacionalidad hay gente buena y mala pero ya es la cultura de cada país y los marroquíes, la manera como tratan a las mujeres... En el club de Barcelona era prohibido ir con marroquíes, ellos entraban tomaban una copa, pero nosotras no podíamos acercarnos a la habitación con ellos, lo que ya nos daba algo de seguridad.

E, em uma mesma região, de acordo com as entrevistadas, há uma ampla diversidade entre os freqüentadores de clubes e da prostituição de rua. Segundo elas, em Barcelona os clientes dos clubes tendem a ser espanhóis e de outros países da comunidade européia. Na rua haveria clientes com menos recursos, migrantes africanos (marroquinos, argelinos) e de diversos países "pobres" (Índia, Paquistão, Polônia) e espanhóis muito jovens (na casa dos 20 anos) ou bem mais velhos (de 60 ou mais anos). Nas palavras de uma brasileira que trabalha neste setor, em Barcelona: "Tenho clientes de 18, de 20. Até 90. No Brasil poucos velhos vão foder, mas aqui... Esses de 80, 90 eles querem carinho. Porque o homem, ele não vem só para foder, entendeu?".

Levando em conta essa diversidade, as percepções dos clientes vinculadas às nacionalidades das trabalhadoras não são generalizáveis. Contudo, o valor concedido à nação de origem em diferentes segmentos de trabalho sexual aponta para um ponto em comum: a relevância da va- 
riedade sobre a singularidade. O diálogo com um cliente espanhol de 44 anos, residente em Barcelona, que freqüenta uma vez por mês os clubs e ocasionalmente consome serviços sexuais nas estradas, dá uma idéia desses critérios:

Entrevistado: ... me he separado y esto... me da pereza comenzar nada... y no quiero abandonar mi vida sexual... Voy siempre al mismo lugar... Allí hay de todos los colores... rusas, belgas o rumanas, y rubias hasta negras, deben ser africanas o de Brasil. de Ecuador, de cualquier país. Lo que menos hay... son españolas... Muy provocativas... y ellas siempre vienen a disputar los clientes no? [...].

Adriana: Cuéntame, con chicas de qué nacionalidad estuviste?

Entrevistado: Pues seguro, seguro con una rumana, una rusa, albanesa, ecuatoriana, de Bolivia, de Venezuela, morenas así son estas chicas, brasileña, Argentina...

Adriana: Encontraste alguna diferencia en relación a la nacionalidad de las chicas?

Entrevistado: ... que va, son todas iguales, al final es todo igual. Al final todo es caricias, felación y penetración. A la hora de elegirla si, a ver la mas bonita. Después no quiere decir ni que lo haga mejor, ni que esté más buena... Algunas son más profesionales que otras... Yo valorizo el profesionalismo. La nigeriana no era nada profesional, tal vez porque para ella follar sea más natural. Las de Europa del Este son más profesionales.

Ao fazer referência a um local de prestação de serviços inteiramente diferente, na rua, na região do Raval, em Barcelona, uma baiana, muito delgada e morena, de 42 anos, alude em outros termos à dimensão da variedade.

Há jovens muito bonitas, realmente, cada menina que tem aí... Para Barbie só falta a caixa. Porque realmente são bonitas de cara, de cabelo, de corpo, de tudo. A maioria é da Romênia. Mas, aqui eles [os clientes] não tem preferência de nada, nem de idade, nem de cor, nem de nada.

Como as trabalhadoras do sexo brasileiras recriam as convenções vinculadas à etnicidade no quadro dessas percepções?

\section{Recriando imagens corporais}

No espaço escuro de um clube em Las Cortes, um bairro tradicional de prostituição, no centro de Bilbao, algumas mulheres estão sentadas na barra, outras em mesinhas contra as paredes. É cedo, não há clientes, mas umas vinte garotas aguardam por eles. Minha acompanhante pára diante de uma loura e diz: "ela é brasileira". Pergunto pelas nacionalidades das outras garotas. Ela vai assinalando os grupos. E me dou conta de que estão agrupadas por nacionalidade. Colombianas em um canto. As louras do Leste Europeu em outro. As brasileiras estão no fundo. Minha acompanhante me chama para o fundo, junto a outras duas louras... São duas irmãs, de Rio Grande do Sul. Vieram a Bilbao no início dos anos 90 [...]. "O serviço está fraco", dizem, "há poucos clientes, muita concorrência...". Pergunto sobre as nacionalidades mais freqüentes nos clubes, em Bilbao. Elas dizem colombianas e brasileiras. Acham que os homens preferem as brasileiras, porque são mais carinhosas, se preocupam mais com eles e, também, porque são mais naturais. Pergunto, "como?". Elas dizem: "olha para a gente!". A mais velha tem o cabelo pintado. A mais jovem, um pouco mais magra, parece ser loura natural. As duas usam maquiagem muito suave, têm bolsas pequenas, estão de calça jeans, blusa de lã e jaqueta e calçam sapatos baixos. A mais jovem está de tênis. Elas mostram os pés e dizem: "nós estamos sempre assim". Segundo elas, as colombianas, não: "usam saltos altíssimos, muita maquiagem, muito ouro e só estão interessadas no dinheiro, só querem tirar dinheiro dos clientes". Quando saímos do clube comento com minha acompanhante a inimizade entre brasileiras e colombianas. Achando graça ela diz: "é assim mesmo, não sei por quê, mas não ficam juntas de jeito nenhum, que nem gato e cachorro" (Diário de Campo, Bilbao, 12 de novembro, 2004).

A disputa por clientes se expressa na concorrência entre estilos de corporalidade, em contextos em que as convenções eróticas freqüentemente indicam o privilégio de uma certa competência sobre a "sensualidade natural" (que inclui a noção de "caliente"), atribuída às brasileiras. Os estilos corporais dessas mulheres, contudo, não são homogêneos. Eles mantêm relações com os gostos atribuídos à clientela diversificada em um ou outro segmento da indústria do sexo. De acordo com as entrevistadas, nos clubes valorizam-se a juventude e determinados estilos corporais. 
A relevância da idade é registrada por brasileiras na faixa dos 40 anos de idade, que acabaram optando pelo trabalho na rua. Segundo elas, a idade, considerada "avançada", no Brasil, estava tornando-se um empecilho para ganhar dinheiro no país e apareceu como obstáculo também nos clubes espanhóis. De acordo com uma entrevistada de 48 anos, originária de Minas, loura, de olhos verdes, pele clara e "esticada" com botox, cadeiras largas e nádegas volumosas, que trabalha no período diurno, na região do Raval, em Barcelona:

Tinham me dado um endereço aqui... em La Coruña. Só que é tudo clube. E mulher com mais idade aqui não ganha dinheiro dentro de clube. Quando eu cheguei, vi o ambiente e falei... muita menina nova. Aqui onde eu trabalho tem mulher de 70 anos... No Brasil, os homens têm aquela mentalidade da mulher novinha de 18 anos, 20 anos. Na Europa não, entende? Aqui é totalmente diferente. Se você tiver 70 anos você ganha dinheiro... Arruma marido também... Porque os brasileiros não gostam de mulher mais velha... Nem de graça... Não é? Aqui não.

Uma garota originária de Natal, de 24 anos, morena, esguia, de cabelo liso e comprido e enormes olhos negros, que ingressou no trabalho nos clubes de Bilbao aos 18 anos, explica qual é o tipo físico selecionado, nessa região do Brasil, para esses espaços: "Éramos três, mas viemos duas porque minha prima, afinal, como era um pouco gordinha, eles desistiram e mandaram só duas, porque éramos magrinhas, morenas".

Neste universo povoado por estrangeiras de diversas nacionalidades, a cor, porém, aparece como um adereço a mais, sem ser determinante nas escolhas, à exceção da negritude, que freqüentemente é rejeitada. Nesses casos, porém, o racismo tende a ser expresso como rejeição a traços culturais. As nigerianas são rechaçadas, em diversos espaços, enquanto nigerianas e, portanto, selvagens, e não necessariamente enquanto negras. Esse "primitivismo" manifesta-se em uma produção corporal em que os cortes no corpo e a ablação genital aparecem como inadequados para os padrões eróticos. O que se rejeita é a dissonância associada à nacionalidade e não à cor da pele. A vinculação entre racismo e nacionalidade é claramente percebida pelas trabalhadoras do sexo brasileiras. Nos termos de uma mulata carioca, de 38 anos, cor de chocolate claro, com olhos verdes, efeito produzido pelo uso de lentes de contato, e longuíssimos cachos dourados criados mediante a utilização de extensões, extremamente cálida:

Aqui, o racismo é diferente que no Brasil, não passa por cor, mas por nacionalidade. Há lugar no qual equatoriano não pode entrar, não importa se mais claro ou mais escuro, ou mouro não pode. Já se é brasileiro, é difícil ter problema. Eles gostam do Brasil, está na moda. Ronaldinho. Carlinhos Brown. Europeu gosta de morena, mas o que mais gostam em mim, como em outras brasileiras, é que sou carinhosa e alegre.

No quadro dessa diversidade, as percepções das entrevistadas convergem em considerar que o temperamento alocado a seus estilos de feminilidade é o principal aspecto que as favorece na inserção na indústria do sexo na Espanha. Essa percepção está presente em trabalhadoras do sexo de todas as idades, trabalhando em clubes, na rua ou em pisos, em diferentes partes do país. Entre as que oferecem serviços sexuais em clubes uma certa valorização estética que exclui a gordura é tida como um trunfo, em detrimento de outras concorrentes latino-americanas, particularmente as colombianas. Descrevendo as relações entre nacionalidades em um clube onde trabalhou, e a corporificação de uma suposta superioridade brasileira, a jovem entrevistada de Natal explica:

Tinha mais colombianas e brasileiras. E tinha sempre aquilo de brasileira em um canto, venezuelana em outro, colombiana em outro, africana em outro, sabe?... Era tipo um enfrentamento. As brasileiras não gostam das colombianas... Os homens, acho, preferem as brasileiras... É dito por todos, que são mais carinhosas, mais divertidas, dizem. E que mais? Que são mais magrinhas, dizem que entre as colombianas, têm muitas gorditas.

As entrevistadas que desempenham suas atividades na rua assinalam que as preferências dos clientes não estão ancoradas necessariamente em aspectos estéticos, nem vinculados à cor. De acordo a entrevistada baiana:

A preferência deles é que a mulher seja carinhosa e trate eles bem e seja limpa... Acho que cinqüenta por cento deles, eles sempre ficam mais com a 
gente. Porque acho que eles se realizam mais...

Essas escolhas tampouco aparecem associadas a um domínio, a um saber específico das brasileiras no que concerne a práticas sexuais. Segundo a trabalhadora sexual de Minas:

[...] [as outras] por exemplo, para o homem gozar na boca delas sem camisinha, não passa nada, normal. E brasileira já não faz isso... Há essas diferenças. E aí os espanhóis gostam muito dessas anarquias... A gente não faz. Só que tem o outro lado, que a gente é mais carinhosa com os homens, é amável.

Acusar mulheres de outras nacionalidades de realizarem qualquer tipo de prática sexual é um recurso utilizado por trabalhadoras do sexo. No estudo de Oso Casas e Ulloa Jiménez (2001), as prostitutas colombianas lançam essa acusação às brasileiras e marroquinas. Entretanto, o que interessa destacar é a idéia das entrevistadas brasileiras de serem singularizadas como brasileiras. Elas afirmam que são portadoras de um temperamento naturalmente sensual e, sobretudo, carinhoso, alegre (com especial inclinação a brincadeiras e risos), bondoso, tranqüilo, no sentido de evitar brigas, e de simpatia. Confrontando as percepções dessas mulheres com as dos consumidores e empresários da indústria do sexo, cabe perguntar sobre o alcance do privilégio que a atribuição desse temperamento outorga em relação às concorrentes. Contudo, é importante sublinhar que na percepção delas o temperamento é o que lhes confere singularidade. De outra maneira, a suposta superioridade concedida à brasilidade em virtude de uma sexualidade exacerbada, associada a um saber específico e vinculada à valorização da cor (morena) é algo secundário.

\section{Exotismos em confronto?}

Que relação tem a noção de exotismo com a produção de imagens corporais das brasileiras nesse contexto? E que sentido tem pensar em confrontos entre exotismos?

De acordo com os escritos clássicos sobre o exotismo, essa noção alude à valorização das diferenças culturais, particularmente da experiên- cia das diferenças mais radicais (Segalen, 1978; Michel, 1996). Esses trabalhos são problematizados há tempos pela produção socioantropológica que sublinha a necessidade de considerar as implicações políticas da noção (Foster, 1982); em leituras éticas no lugar de puramente estéticas (Machado, 2003). Leclerc (1973), discutindo as relações entre exotismo, colonialismo e antropologia, analisou o espírito vitoriano que permeia a visão imperial do mundo realizada pelas metrópoles. De acordo com o autor, o colonialismo, além de expansão e dominação econômica, envolve dominação e etnocentrismo cultural. O processo de tornar o Outro "exótico", característico da visão imperial, deveria ser considerado nessa leitura política.

Levar em conta essa dimensão permite compreender como o Outro racial, étnico ou cultural é dotado de aspectos românticos e, ao mesmo tempo, é oprimido e explorado. Segundo Kempadoo (2004), o exotismo valoriza povos e culturas remotos, alimentando a ilusão de admiração e atração pelo Outro. No entanto, seria uma forma diferenciada de racismo que situa a alteridade em um lugar inferior. Analisando os processos de exotização contemporâneos, a autora chama a atenção para sua especificidade. Para ela esses processos, vinculados a movimentos econômicos e culturais globalizantes, atualizam as leituras imperiais alargando o leque de sexualidades racializadas.

Esse conjunto de referências oferece elementos para pensar nas dinâmicas que envolvem as viagens de turistas à procura de sexo para o Nordeste do Brasil. A idéia de exotismo, que faz parte do universo desses viajantes, está vinculada a uma exacerbação da diferença e intimamente ligada ao erotismo. Vale assinalar que essa relação tem uma longa história nos relatos de viagem "ocidentais", nos quais as viagens aos países do Sul foram consideradas fonte de liberdade erótica (Edwards, 2001). Essa atração, na qual a alteridade é delineada mediante distinções inseridas em nítidas relações de desigualdade, pode adquirir conotações de verdadeira fascinação. Mas, essas "trocas", longe de serem apresentadas apenas como sexo de fácil acesso em qualquer lugar do mundo, são valorizadas como expressão de uma série de singularidades: um estilo de se- 
xualidade específico que, por sua natureza "autêntica", abre vias para o contato "real" com o outro.

Em síntese, embora inferiorize o "Outro", o exotismo destaca sua singularidade. Mas, no âmbito da inserção das brasileiras na indústria do sexo na Espanha, a transformação da diferença em exotismo parece diluir-se. Nesse contexto, a diferença, longe de ser exacerbada, é quase banalizada.

Em cenários onde as convenções do erotismo são regidas por um grau extremo de mercantilização há uma permanente valorização do novo e do diferente. Os empresários acreditam que a inovação e a oferta de novos serviços atraem os clientes, seja oferecendo disfarces (mulheres fantasiadas de estudantes, freiras etc.), seja decorando os quartos dos pisos de maneira temática (Roma Antiga, Egito, Japão) e, ainda, nos clubes, com o sistema de plazas, renovando a oferta de novas mulheres cada 21 dias (Pons, Rodriguez e Vega, 2002). A nacionalidade faz parte dos critérios de novidade e diversificação presentes nesta lógica. Este ponto resulta particularmente claro nos depoimentos dos clientes do site www.hotvalencia.com. A tendência presente em parte significativa dos relatos de contatos sexuais com mulheres de um amplo leque de nacionalidades é não repetir a experiência, procurando permanentemente um novo corpo, uma nova nacionalidade.

Neste quadro, em que a excitação está associada à possibilidade de escolher entre inúmeras "marcas" de um mesmo produto e os critérios de seleção muitas vezes sugerem o privilégio da "eficácia" no menor tempo possível, a "sensualidade natural" vinculada à cor (morena), relativamente esvaziada de valor, desloca-se, ocupando um lugar secundário. E a força do exotismo parece desvanecer-se na valorização da variedade.

\section{Conclusão}

As convenções de erotismo envolvendo a brasilidade adquirem conotações particulares em contextos diferenciados, no âmbito da transnacionalização do mercado sexual. As imagens corporais produzidas nesses contextos são iden- titárias, marcadas pela nacionalidade. No entanto, as categorias utilizadas nessa construção e o peso a elas concedidas são diferenciados, revelando a adequação a diversos mercados em países com relações históricas diferenciadas com o Brasil e aos nichos específicos da indústria do sexo.

As imagens corporais produzidas na indústria do sexo na Espanha acionam imbricações entre categorias que se diferenciam daquelas presentes em contextos de turismo sexual internacional, no Brasil. Por sua vez, as imagens corporais produzidas em nichos médios e nos mais baixos desse mercado variam em função de entrecruzamentos diferenciados entre idade e padrões estéticos. Contudo, e de maneira aparentemente paradoxal, no quadro da concorrência com a oferta de serviços sexuais de mulheres de diversas nacionalidades, a marca mais intensa percebida pelas entrevistadas inseridas em espaços vinculados a uns e outros nichos remete a um estilo de feminilidade em que a nacionalidade se expressa em traços de temperamento singularizados por aspectos que remetem à sensualidade "natural", à alegria e à afetuosidade. Mas, esses traços distam de ser vinculados a uma sexualidade exacerbada e associada a um saber sexual específico, conectada com a idéia da "mulata" que supostamente caracteriza o Brasil no âmbito transnacional.

No marco da inserção na indústria do sexo na Espanha, essas qualidades estão associadas a uma diversificação na oferta que é apreciada por empresários e por clientes. No entanto, o valor atribuído a essa diferença a distancia da idéia de singularidade que permeia as formulações do exotismo.

\section{Notas}

1 Essa pesquisa foi viabilizada pelo apoio da Fapesp ao projeto temático "Gênero, corporalidades", ao qual está vinculada, e pelo apoio a estágio de pósdoutoramento concedido pela Capes, na Universidad Autónoma de Barcelona. Agradeço especialmente a Verena Stolcke, Dolores Juliano, Dilma Felizardo, Katia Juncks, Cristina Garaizával, Laura Agustín, Isabel Holgado, Constancia, Carla, Justine, Fátima, Lurdes Perramon e a integrantes de diversas organizações: Irmãs Oblatas, Licit, Ambit Dona, Hetaeira, Comisión Ciudadana Antisida de Biskaia. 
2 Para as diversas acepções do termo transnacional em abordagens feministas, ver Ata Aidoo et al. (2000), Phizacklea (2003) e Anthias (2000).

3 Quando se fala em "indústria do sexo", alude-se à sua dimensão, à capacidade de gerar renda, às interrelações com outras grandes indústrias e infraestruturas e à diversidade de negócios relacionados com o sexo, alguns dos quais apresentam formas de organização industrial e outros poderiam ser considerados quase "artesanais" (como no turismo sexual) (Agustín, 2001).

4 A Espanha (assim como Portugal) é um dos países da Europa que suscitam maior preocupação no Brasil no que se refere a esse tipo de migração; uma inquietação ligada à sua associação com o tráfico internacional de pessoas (Piscitelli, 2006).

5 O trabalho de campo envolveu a observação em entidades que apóiam trabalhadoras/es do sexo nas cidades de Barcelona, Madri e Bilbao e em espaços destinados à oferta desses serviços (na rua e em clubes); entrevistas em profundidade realizadas com dez agentes vinculados a essas entidades, à indústria do sexo, ao Consulado de Brasil em Barcelona e à Comisaría General de Extranjeria; com dez mulheres e "trans" (termo êmico que se refere ao conjunto de pessoas consideradas travestis, transexuais ou transgêneros) que têm oferecido serviços sexuais nessas cidades; entrevistas de controle com duas brasileiras inseridas nas mesmas redes de relações que não oferecem serviços sexuais; e com dois "clientes" espanhóis. A pesquisa abarcou a análise de fontes e de material secundário, dados estatísticos sobre migração, pesquisas acadêmicas e relatórios sobre prostituição, material jornalístico e material de um site espanhol destinado a clientes de prostitutas.

6 A legislação espanhola trata da prostituição como delitos contra a liberdade sexual, limitando-os às situações extremas, nas quais falta o consentimento (Código Penal de 1995, artigo 188.1). O proxenetismo é penalizado, mas, diferentemente do Brasil, segundo Ruth Mestre (2004), é entendido como atividade de terceiros, que coagem uma pessoa a prostituir-se mediante engano ou abuso de poder.

7 Na região de Navarra, em 2003, apenas 5\% do total de pessoas que ofereciam serviços sexuais trabalhavam na rua; $85 \%$, em clubes, e em torno de 10\%, em pisos (Arróniz et al, 2003) . Já estudos anteriores realizados na Galícia apontam para a absoluta escassez de trabalhadoras sexuais nas ruas (Oso e Ulloa, 2001).
8 Nesse sentido, é interessante comparar as etnografias sobre modalidades de prostituição realizadas na segunda metade da década de 1990 e trabalhos mais recentes. As entrevistadas no excelente estudo de Medeiros (2000), que ofereciam serviços sexuais na rua no centro de Barcelona, eram majoritariamente nascidas na Espanha.

9 Laura Agustín (2001) chama a atenção para a longa tradição, na Espanha, de migrações internas e também entre países europeus vinculadas à venda de sexo. Tais movimentos persistem, mas não aparecem em estudos que consideram migrantes apenas as pessoas do Terceiro Mundo e dos países do Leste Europeu.

10 Relatórios parciais aludem a percentuais mais elevados e diversificados segundo as regiões. Segundo a Guardia Civil, em 2000, nos clubes de estrada de várias províncias, $90 \%$ das trabalhadoras seriam estrangeiras (Agustín, 2001). Um estudo realizado no país Basco, em 2002, contemplando clubes, prostituição de rua e pisos, indica que, nessa região, entre 80 e $90 \%$ das mulheres eram estrangeiras, procedentes principalmente de América Latina $(71,8 \%)$; depois as espanholas $(17,9 \%)$, seguidas por africanas $(5,1 \%)$ e portuguesas $(5,1 \%)$ (Emakunde, 2002). Segundo Dolores Juliano (2004), em meados de 2003, registros dos Mossos de Escuadra, na Catalunha, considerando apartamentos, clubes e ruas, indicam que $23 \%$ das mulheres seriam espanholas, 2\%, de outros países da comunidade européia, e 75\%, de migrantes não comunitárias, entre as quais 30\% oriundas da África subsahariana, 30\%, da América do Sul, 30\%, dos países do Leste, $8 \%$, magrebíes, e $2 \%$, de outros países.

11 Essa cifra pode ser plausível, considerando os dados elaborados pela Comisaría General de Extranjería y Documentación. De acordo com essas informações, em 2004 o total de cidadãos brasileiros que retornaram ao Brasil mediante a intervenção da polícia (devoluciones, expulsiones e retornos) foi de 2.342, um número elevado se comparado com os 798 casos registrados em 2003. Vale lembrar que as cifras se referem ao total de cidadãos deportados, não havendo separação por sexo ("Registro de dados de cidadãos brasileiros", gentilmente enviados por e-mail pelo órgão referido, em 15/2/2005).

12 E, se a atenção nacional e internacional se detiver em mulheres que oferecem serviços sexuais e, eventualmente, foram vítimas do tráfico, a informação, colhida por ONGs espanholas e referenda- 
da pela presente pesquisa, mostra que há uma significativa incidência de "trans" brasileiras, algumas muito jovens, não só nas ruas ou em pisos, mas também em espaços considerados mais "difíceis e duros", como o Campo do Barça, em Barcelona, e a Casa de Campo, em Madrid.

13 Os demais depoimentos, acessados no site em maio de 2006, referem-se a 42 mulheres da comunidade européia - principalmente espanholas (38) -, 49, provenientes da Rússia e do Leste Europeu - com especial destaque para Romênia (28) -, 6, da África, e 5, da Ásia.

14 No momento em que foi realizada esta pesquisa, tal instituição abarcava em torno de 10\% dos clubes.

15 Sobre colombianas em Galicia ver Riopedre (2004).

16 Em 2004, um espanhol com baixo nível de escolaridade ou um migrante regular recebia no mercado de trabalho de Barcelona entre 6 e 8 euros por hora, enquanto um migrante irregular (independentemente de seu grau de escolaridade) recebia aproximadamente a metade (Juncks, 2004). Essa diferença obriga os migrantes irregulares a trabalhar durante jornadas extenuantes para poder sobreviver, enviar dinheiro para o Brasil (o que todas as entrevistadas fazem) e/ou poupar dinheiro para investir ou retornar ao país.

17 É claro que não se pode generalizar a maneira pela qual as mulheres percebem tal estigma. Para uma leitura dos efeitos causados pelo preconceito em mulheres marroquinas, ver Rodríguez Martínez e Lahbabi (2005).

18 Destaco o contexto específico ao qual me refiro porque estudos realizados na década de 1990 (por exemplo, Dias Filho, 1998) somados a trabalhos mais recentes sobre turismo sexual apontam como cada contexto implica em traçados bastante diferenciados(Silva e Blanchette, 2005; Ribeiro e Sacramento, 2006).

\section{BIBLIOGRAFIA}

AIDOO, Ama Ata; ACOSTA-BELÉN, Edna; BASU, Amrita; CONDÉ, Maryse; PAINTER, Nell \& SAADAWI, Nawal El. (2000), "Feminists speak on feminism, race and transnationalism". Méridians: feminism, race, transnationalism, 1 (1): 1-28.
AGUSTÍN, Laura. (2001), "Mujeres inmigrantes ocupadas en la industria del sexo", in Colectivo IOÉ (ed.), Mujer, inmigración $y$ trabajo, Madri, Imserso. . (2005), Trabajar en la industria del sexo. Donosti, Tercera Prensa.

. (2006), "The disappearing of a migration category: migrants. Who sell sex". Journal of Ethnic and Migration Studies, 32 (1): 29-47.

ALFONSO, Louise Prado. (2006), Embratur: formadora de imagens da nação brasileira. Dissertação de mestrado, Campinas, Unicamp (mimeo.).

ANTHIAS, Floya. (2000), "Metaphors of home: gendering new migrations to Southern Europe", in Floya Anthias e Gabriela Lazaridis (orgs.), Gender and migration in Southern Europe: women on the move, Oxford, Berg.

APPADURAI, Arjun. (1996), Modernity at large: cultural dimensions of globalization. Minneapolis, University of Minnesota Press.

ARRÓNIZ, Asun Roldán; ORMAETXEA BELLO, Koro \& ASTRAIN GALLART, Kepa. (2003), "El oficio de la prostitución en Navarra: estigmas y modo de vida". Consultado no site http://www.mugak .eu/ef_etp_files/view/Prostitucion_en_ Navarra.pdf?package_id=2392.

ASSIS, Gláucia de Oliveira. (2004), De Criciúma para o mundo: rearranjos familiares $e$ de gênero nas vivências dos novos migrantes brasileiros. Tese de doutorado, Campinas, Unicamp (mimeo.).

CECRIA. (2000), "Tráfico de mulheres, crianças e adolescentes para fins de exploração sexual no Brasil". Projeto de pesquisa, Brasília (mimeo.).

CORRÊA, Mariza (1996), "A invenção da mulata". Cadernos Pagu, 6-7: 35-51.

DIAS FILHO, Antônio Jonas. (1998), Fulôs, Ritas, Gabrielas, Gringólogas e garotas de pro- 
grama: falas, práticas, textos e imagens em torno de negras e mestiças, que apontam para a construção da identidade nacional, a partir da senxualidade atribuída à mulher brasileira. Dissertação de mestrado, Salvador, Universidade Federal da Bahia (mimeo.).

EDWARDS, Justin D. (2001), Exotic jouneys: exploring the erotics of U.S. travel literature, 1840-1930. Hanover, University Press of New England.

EMAKUNDE. (2002), La prostitución ejercida por las mujeres en la C.A.P.V. Vitória, Gasteiz, Emakunde (mimeo.).

EMRICH PINTO, Glycia. (2005), "Esculturas em bronze: gênero e sexualidade nas propagandas turísticas voltadas para o público brasileiro". Relatório apresentado ao PIBIC, Campinas, Unicamp (mimeo.).

FOSTER, Stephen William. (1982), "The exotic as symbolic system". Dialectical Anthropology, 7 (1): 21-31.

GARAIZABAL, Cristina. (2005), "O estigma da prostitución". Andaiana, site www.anda inamulleres.org/artigresul_2php?tiduo, consultado em janeiro de 2007.

JULIANO, Dolores. (2004), "La construcción de la identidad a partir de sus límites". Informe Final, Grupo Multiculturalismo y Género, Barcelona (mimeo.).

JUNCKS, Kátia Regina. (2004), La fomación bistórica de la clase obrera en la Barcelona del siglo XXI: un pequeño diálogo con E. P. Thompson. Tesina, Universidad Autónoma de Barcelona (mimeo.).

KEMPADOO, Kamala. (2004), Sexing the Caribbean: gender, race and sexual labor. Nova York, Routledge.

LECLERC, Gérard. (1976), Crítica da antropologia. Lisboa, Estampa.

LIM, Lin Leann. (2004), "El sector del sexo: la con- tribución económica de una industria", in Raquel Osborne (ed.), Trabajadoras del sexo: derechos, migraciones y tráfico en el siglo XXI. Barcelona, Ediciones Bellaterra.

MACHADO, Igor José de Renó. (2003), Cárcere público, processos de exotização entre imigrantes brasileiros no Porto, Portugal. Tese de doutorado, Campinas, Unicamp (mimeo.).

MAIA, Susana. (2007), "Performing seduction and national identity: Brazilian erotical dancers in New York", in Sonia Alvarez e Claudia Lima Costa (orgs.), Translocalities, Duke University Press (forthcoming).

MEDEIROS, Regina de Paula. (2000), Hablan las putas: sobre prácticas sexuales, preservativos y Sida en el mundo de la prostitución. Bilbao, Virus.

MESTRE, Ruth. (2004), "Las caras de la prostitución en el Estado español: entre la Ley de Extranjería y el Código Penal", in Raquel Osborne (ed.), Trabajadoras del sexo: derechos, migraciones y tráfico en el siglo XXI, Barcelona, Ediciones Bellaterra.

MICHEL, Andreas. (1996), "The subject of exoticism: Victor Segalen's Equipée". Surfaces, 1 (1), site www.pum.montreal .ca/revues/surgaces/vol16/michel.html, consultado em 22/10/2005.

MINISTÉRIO DE TRABAJO y Asuntos Sociales. (2004), "Boletin estadístico de Extranjeria y Inmigración”, 3, Madri.

OSO CASAS, Laura. (2005), "Mullers inmigrantes y prostitución en Galicia”. Andaiana, site www.andainamulleres.org/artigresul_2p hp?tiduo, consultado em janeiro de 2007.

OSO CASAS, Laura \& ULLOA JIMENEZ, Marcela. (2001), "Tráfico e inmigración femenina desde la voz de las mujeres inmigrantes", in Elena Bonelli Jáudenes e Marcela Ulloa Jiménez (orgs.), Tráfico e inmi- 
gración de mujeres en España, colombianas y ecuatorianas en los servicios domésticos y sexuales, Madri, ACSUR/Las Segovias, site www.acsur.org, consultado em janeiro de 2007.

PHIZACKLEA, Annie. (2003), "Gendered actors in migration", in Jacqueline Andall (ed.), Gender and ethnicity in contemporary Europe, Oxford, Berg.

PISCITELLI, Adriana. (2004): "On gringos and natives, gender and sexuality in the context of international sex tourism". Vibrant - Virtual Brazilian Anthropology, 1

(2005), "Introdução". Cadernos Pagu, Mercado do Sexo, 25: 7-25.

. (2006) "Indícios de tráfico de pessoas no universo de deportadas e não admitidas que regressam ao Brasil via aeroporto de Guarulhos", in Secretaria Nacional de Justiça (ed.), Pesquisas em tráfico de pessoas, parte 2, Brasília.

(no prelo), "Sexo tropical em contextos do 'Primeiro Mundo",, . Revista Estudos Feministas.

PONS, Ignasi. (2003), Condicions de treball en la nova indústria de la prostitució: els clubs d'alterne. Barcelona, Universitat de Barcelona (mimeo.).

PONS, Inaci; RODRÍGUEZ, Roser \& VEGA, Sonia. (2002), "Trabajo sexual", Informe Cataluña, Departamento de Sociología i Análisis de las Organizaciones, Universidad de Barcelona (mimeo.).

PONTES, Luciana. (2004), "Mulheres brasileiras na mídia portuguesa”. Cadernos Pagu, Cara, Cor, Corpo, 23: 229-257.

RIBEIRO, Fernando Bessa \& SACRAMENTO, Otávio. (2006), "A ilusão da conquista: sexo, amor e interesse entre gringos e garotas em Natal". Trabalho apresentado no III Congresso da Associação Portuguesa de Antropologia, Lisboa, 6/8 abr. (mimeo.).
RIOPEDRE, Pepe. (2004), Mara y sus amigas: investigación sobre la prostitutión en Galicia. Lugo, Manuscritos.

RODRÍGUEZ MARTÍNEZ, Ana \& LAHBABI, Fátima. (2005), "Autonomía e límite da autonomía das traballadoras do sexo marroquinas". Andaiana, site www.an dainamulleres.org/artigresul_2php?tidu, consultado em janeiro de 2007.

ROLDAN ARRÓNIZ, Asun et al. (2003), "El oficio de la prostitución en Navarra: estigmas y modo de vida". Consultado no site http://euskalherria.indymedia.org/eu/2 003/06/7419.shml, em janeiro de 2007.

SEGALEN, Victor. (1978), Essai sur le exotisme. Paris, Fata Morgana.

SILVA, Ana Paula da \& BLANCHETTE, Thaddeus. (2005), "Nossa Señora da Help: sexo, turismo e deslocamento transnacional em Copacabana”. Cadernos Pagu, Mercado do Sexo, 25: 249-281.

TERRON, Ana. (2004), "Migraciones y relaciones con países terceros". Documento do Cidob, Série Migraciones, 2, Barcelona.

THORBEK, Susanne \& PATTANAIK, Bandana. (2002), Transnational prostitution: changing global patterns. Londres, Zed Books. 


\section{CORPORALIDADES EM CON- FRONTO: BRASILEIRAS NA INDÚSTRIA DO SEXO NA ESPANHA}

Adriana Piscitelli

Palavras-chave

Indústria do sexo; Prostituição; Migração; Gênero; Corporalidade; Exotismo

Tomando como referência a inserção de brasileiras no mercado do sexo espanhol, neste texto analiso como corporalidade e gênero se integram na intensa concorrência que têm lugar na indústria transnacional do sexo contemporânea. Traço, primeiro, as trajetórias dessas mulheres, considerando as implicações culturais, políticas e econômicas dessa modalidade de migração. Criando uma perspectiva comparativa a partir da consideração das conceitualizações acionadas nos relacionamentos entre estrangeiros e brasileiras no marco da indústria do sexo no Brasil, considero, depois, o significado da alteração de contextos para a articulação das diferenciações permeando as interações das brasileiras que se inserem no mercado do sexo espanhol. Essa questão é elucidada explorando como as construções de gênero, nacionalidade/ etnicidade, "raça", classe e idade são acionadas nas interações comerciais estabelecidas por essas migrantes.

\section{CONFRONTING CORPORALI- TIES: BRAZILIAN WOMEN IN THE TRANSNATIONAL SEX INDUSTRY}

Adriana Piscitelli

\section{Keywords}

Sex industry; Prostitution; Migration; Gender; Corporality; Exoticism.

Taking as reference Brazilian women's insertion in the Spanish sex market, in this article I analyze how corporality and gender take part in the contemporary transnational sex industry. First, I consider these women's trajectories, considering the cultural, political and economic implications of this modality of migration. Then, creating a comparative perspective by contemplating the conceptualizations that permeate relationships between foreigners and Brazilian women in the Brazilian sex industry, I consider the meaning of shifting contexts regarding the differentiations that permeate their incorporation in the Spanish sex market. I reflect on this exploring how constructions of gender, nationality, ethnicity, "race" class, and age are activated in the commercial interactions of those migrants.
CORPORALITÉS EN CONFRONTATION: LES BRÉSILIENNES DANS L'INDUSTRIE DU SEXE EN ESPAGNE

Adriana Piscitelli

\section{Mots-clés}

Industrie du sexe; Prostitution; Migration; Genre; Corporalité; Exotisme.

En prenant pour référence l'insertion de brésiliennes sur le marché du sexe espagnol, cet article analyse la façon par laquelle corporalité et genre s'intègrent dans la concurrence intense qui s'établit dans l'industrie transnationale contemporaine du sexe. Il commence par tracer la trajectoire de ces femmes, en prenant en compte les implications culturelles, politiques et économiques de cette modalité de migration. Après avoir créé une perspective comparative à partir de la considération des conceptualisations mises en jeu dans les relations entre étrangers et brésiliennes dans le cadre de l'industrie du sexe au Brésil, il analyse de quelle façon l'altération de contexte modifie les significations attribuées aux notions qui s'insèrent dans les interactions des brésiliennes sur le marché du sexe espagnol. Cette question est résolue par l'indication de la façon par laquelle les constructions de genre, nationalité/ethnicité, "race", classe et âge sont mobilisées dans les interactions commerciales établies par ces migrantes. 